\title{
Particle Dispersion Within a Deep Open Cast Coal Mine
}

\author{
Sumanth Chinthala and Mukesh Khare \\ Indian Institute of Technology Delhi \\ India
}

\section{Introduction}

Dust generation and its dispersion has been the major concern in ambient air quality in deep cavities such as open cast mines. Major mining activities in deep open pit coal mines range from exploration to the processing of end product that primarily contribute particulate matter $(\mathrm{PM})$, dominantly $\mathrm{PM}_{10}$ leading to the problem of air pollution and related health hazards (Falk and Jurgelski, 1979; Pless-Mulloli et al, 2000). As a result, the simulation of dispersion characteristics within the deep open pit coal mines becomes essential to analyze the complex wind flow patterns that significantly affect the dispersion of $\mathrm{PM}_{10}$. The dispersion equations developed within the deep pit boundary provide a reasonable accurate estimate of $\mathrm{PM}_{10}$ dispersion within the near field region of the deep open pit coal mines (Silvester et al, 2009). The fundamental equations of continuity and momentum describe the in pit dispersion mechanisms within the atmospheric boundary layer (ABL). In addition, the meteorological conditions within the deep open pit coal mine are significantly affected by temperature (stability) and roughness conditions which ultimately generate complex dispersion phenomenon including separation of atmospheric boundary layer, recirculation, resuspension and settling of $\mathrm{PM}_{10}$ (Bitkolov, 1969; Grainger and Merony, 1993). However, the in-field measurements of $\mathrm{PM}_{10}$ within the deep open pit coal mines are constrained by safety regulations, complex geometry of the pit, uncontrolled wind flows and different operation types that make it extremely difficult to carry out monitoring of the $\mathrm{PM}_{10}$ conventionally (Roy et al, 2011). Further, the simulation of dispersion characteristics using the fundamental governing equations may require modifications to incorporate the in pit microclimatic effects on the flow regimes (Markov et al, 1978; Aloyan et al, 1982). Therefore, it is essential to analyze and evaluate microclimatic parameters including the wind turbulence and shear in order to simulate the dispersion of $\mathrm{PM}_{10}$ (Turner, 1994). This chapter presents a comprehensive description of the dispersion mechanisms in the deep open pit coal mines considering the topographic, thermal and meteorological factors.

\section{Dispersion mechanism in deep open pit coal mine}

Dispersion mechanisms consist of diffusion and advection processes. The atmospheric motions transport and diffuse the pollutants that are released from sources. Richardson (1926) 
has investigated the dispersion characteristics by using tracers. The fundamental scaling and power laws have been studied by Taylor (1921) and Roberts (1923). The temporal and spatial scales of motion serve to disperse pollutants in the atmosphere by mixing and thus lowering the ambient pollutant concentrations (Turner, 1994). Mikkelson (2003) and Hanna et al (1982) have discussed various aspects of dispersion and associated parameters that are primarily influenced by source dimensions, buoyancy and momentum of the release, roughness and surrounding topography, atmospheric stability and large scale differential heating. In case of $\mathrm{PM}_{10}$ its dispersion is additionally affected by intertial and dynamic forces acting on the particulates acting on them. Open cast coal mining involves various operations e.g overburden removal, drilling, blasting, mineral loading, haulage and unloading that generate particulates due to various mechanisms. It has been observed that out of total particulates generated, the $\mathrm{PM}_{10}$ constitute one-third to half (Ghose \& Majee, 2007; Trivedi et al, 2009). The operations and their contribution to the generation of the particulates have been listed in table 1.

\begin{tabular}{|c|c|}
\hline Operation & $\begin{array}{c}\% \text { of particulates } \\
\text { generated }\end{array}$ \\
\hline Overburden removal & $7 \%$ \\
\hline Top soil removal & $1 \%$ \\
\hline Coal processing & $72 \%$ \\
\hline Coal extraction & $3 \%$ \\
\hline Wind erosion & $17 \%$ \\
\hline
\end{tabular}

Table 1. Contribution of operations to the particulate generation (Ghose \& Majee, 1998)

\section{Flow dynamics in deep open pit coal mines}

The flow in the deep pit coal mine is a special case of a deep cavity flow where shear stresses are dominant (Tani et al, 1961; Chang, 1970). It depends significantly upon the state of the boundary layer ahead of the cavity, pressure and forces due to the flow. Sometimes, vortices are formed in the cavities due to the deflection of part of the separated boundary layer. Cavities are generally classified according to their length to depth (L/D) and length to width $(\mathrm{L} / \mathrm{W})$ ratios, respectively. A cavity is deep, if $\mathrm{L} / \mathrm{D}<1$; and shallow, if $\mathrm{L} / \mathrm{D}>1$; two dimensional if $\mathrm{L} / \mathrm{W}<1$; and three dimensional if $\mathrm{L} / \mathrm{W}>1$ (Larcheveque et al, 2003). The cavity flows are further classified into open type $(\mathrm{L} / \mathrm{D}<10)$ and closed type $(\mathrm{L} / \mathrm{D}>13)$ according to the aspect ratio. In the closed type cavity, the shear layer generated at the leading edge collides with the cavity floor. The layer is reflected from the floor forming the expansion waves and the flow escapes the trailing edge. Therefore, two small separate zones are formed in the cavity. In the open type cavity, the free stream shear layer is reattached to the trailing edge and divides the flow into internal and external flow (Woo et al, 2008). Table 2 describes different types of cavities and their characteristics. 


\begin{tabular}{|c|c|c|c|c|}
\hline $\begin{array}{l}\text { Sl } \\
\text { no }\end{array}$ & $\begin{array}{l}\text { Property } \\
\text { / parameter }\end{array}$ & Shallow & Intermediate & Deep \\
\hline 1 & $\begin{array}{l}\text { Recompression } \\
\text { layer }\end{array}$ & $\begin{array}{c}\text { Not } \\
\text { Investigated }\end{array}$ & Not Investigated & $\begin{array}{c}\text { Decreases with } \\
\text { increased L/D ratio }\end{array}$ \\
\hline 2 & $\begin{array}{l}\text { Boundary layer } \\
\text { and its influence }\end{array}$ & $\begin{array}{c}\text { Not } \\
\text { Investigated }\end{array}$ & Not Investigated & $\begin{array}{c}\text { Bridges the cavity } \\
\text { and has little influence } \\
\text { over the cavity flow } \\
\text { parameters }\end{array}$ \\
\hline 3 & $\begin{array}{l}\text { Redevelopment } \\
\text { length }\end{array}$ & $\begin{array}{l}\text { Redevelopment } \\
\text { is small }\end{array}$ & $\begin{array}{l}\text { Redevelopment is } \\
\text { maximum }\end{array}$ & $\begin{array}{l}\text { Redevelopment is } \\
\text { small }\end{array}$ \\
\hline 4 & $\begin{array}{c}\text { Variation of } \\
\text { coefficient of } \\
\text { pressure }\end{array}$ & Low & Maximum & Low \\
\hline 5 & $\begin{array}{c}\text { Boundary layer } \\
\text { thickening }\end{array}$ & More & Less & More \\
\hline 6 & $\begin{array}{l}\text { Free shear layer } \\
\text { flow }\end{array}$ & $\begin{array}{l}\text { Less strongly } \\
\text { distributed }\end{array}$ & $\begin{array}{l}\text { More strongly } \\
\text { distributed }\end{array}$ & $\begin{array}{l}\text { Less strongly } \\
\text { distributed }\end{array}$ \\
\hline 7 & Drag Coefficient & High & Medium & Low \\
\hline 8 & Flow type & unsteady & Not Investigated & Dead/laminar \\
\hline 9 & $\begin{array}{l}\text { Flow } \\
\text { reattachment }\end{array}$ & $\begin{array}{l}\text { Occurs on the } \\
\text { floor of the } \\
\text { cavity }\end{array}$ & Not Investigated & $\begin{array}{l}\text { Occurs on the rear } \\
\text { shoulder of the cavity }\end{array}$ \\
\hline 10 & $\begin{array}{l}\text { Reynolds } \\
\text { number }\end{array}$ & Large & Medium & Small \\
\hline 11 & Velocity & Large & Medium & Small \\
\hline 12 & Skin friction & Large & Medium & Small \\
\hline 13 & Base pressure & $\begin{array}{l}\text { First decreases } \\
\text { and then } \\
\text { increases }\end{array}$ & Not Investigated & $\begin{array}{l}\text { Constant in the } \\
\text { middle and slightly } \\
\text { irregular in the front } \\
\text { and rear portions }\end{array}$ \\
\hline 14 & $\begin{array}{c}\text { Three } \\
\text { dimensionality of } \\
\text { shear layer flow }\end{array}$ & Slightly & Strongly & Slightly \\
\hline
\end{tabular}

Table 2. Types of cavities and their characteristics (Chowdhary, 1977) 


\subsection{The cavity regions}

The cavity region contains different zones where the boundary layer undergoes various changes (Figure 1). The Upstream zone comprises the developing boundary layer zone which is upstream of the front corner of the notch with a finite approaching boundary layer. Expansion zone is a small zone just downstream of the separation corner where the pressure falls to the base pressure level. In this zone, the inner $10-15 \%$ of the approaching boundary layer adjusts rapidly to expansion at the separation corner and forms a new viscous sublayer slightly below the separation corner. Mixing zone is in the initial part of the free shear layer. The flow is similar to a separated jet type wake and lies between the isoenergic free stream flow and the dividing stream line. This intermediate buffer zone acts as a coupling between the outer free stream flow and the inner dissipative flow and brings about the transport of mass and momentum from the former to the latter. The pressure is nearly constant in this zone. This region is associated with large velocity gradients and substantial viscous activity. After the constant pressure mixing region, the shear layer negotiates the pressure rise which continues up to the reattachment point where a apart of the shear layer gets reversed and forms a recirculating cavity flow. The recirculating cavity flow lies between the separation point and the reattachment point, having a low Reynolds number and a constant static pressure. This zone is called as compression zone. This recirculating cavity flow has also been termed as separation wake. After the reattachment point, the shear layer negotiates the further pressure rise which continues upto the free stream value. This is called as the recompression zone. The flow in the ramp corner as well as in the recompression zone is assumed to be isentropic and invicid. Further, the recompression zone entrains an unsteady vertical flow, which is known as the recompression wake. After the recompression region the flow forms a new uniform stream with a redeveloping zone which becomes fully developed at some distance downstream. Various factors affecting the flow dynamics in the case of deep open pit coal mines have been discussed in subsequent sections.

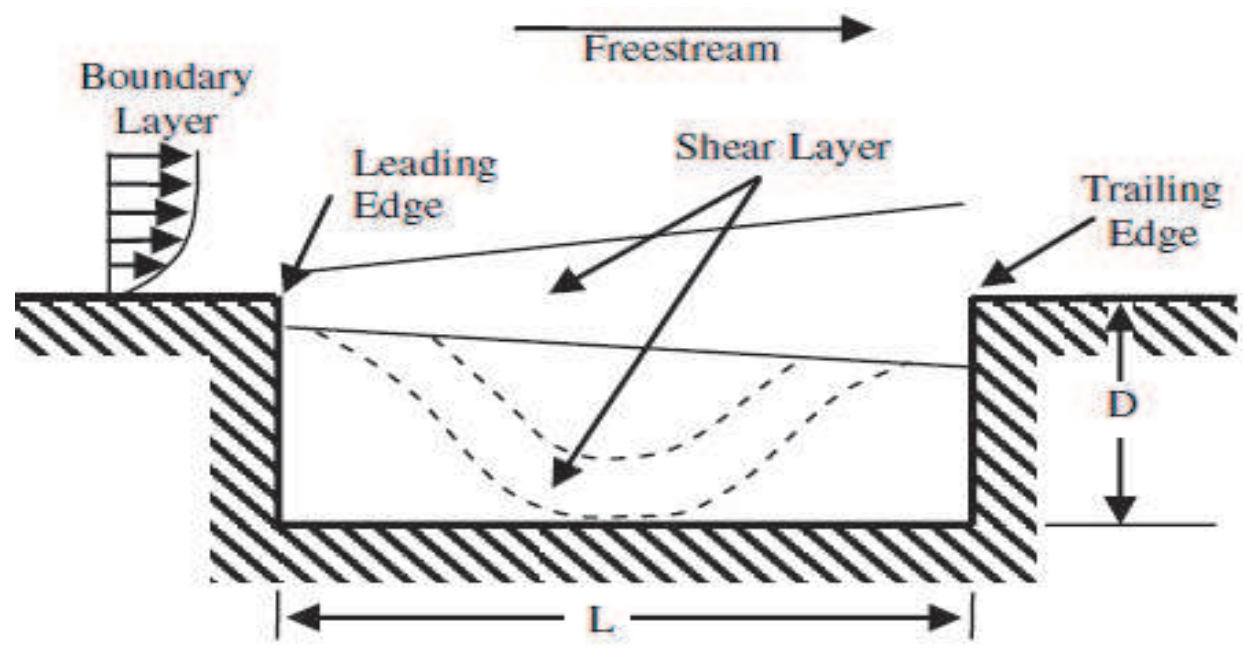

Fig. 1. Cavity flow field operating in open configuration (solid line) and closed configuration (dotted line). Source: Lazar et al, 2008 


\subsubsection{Topographic factors}

The open pit coal mine topography is mostly rugged and uneven. In general, it is a few kilometers wide and more than $50 \mathrm{~m}$ deep. In the case of deep open pits, the depth may be as high as 300-400 meters. The complexity arises due to the presence of overburden dumps, construction of access roads and blasting activities. The topography affects the dispersion of pollutants due to changes in the mean flow (Castro \& Apsley, 1997). It also affects the trajectory of the wind that channels and confine the plume dispersion and also causes flow re-circulations within the pit (Shi et al, 2000; Appleton et al, 2006).

\subsubsection{Slopes \& benches}

Slopes facilitate an easy penetration of the wind because the shape of the pit guides the wind flow (Grainger \& Merony, 1993; Peng \& Lu, 1995). Besides, the slopes play a major role in the reduction of the size of the primary eddies (Mcquain et al, 1994). The presense of slopes also result in increase in the wind speed (Figure 2). Additionally, the faces and elevation of the benches cause the local deflection of the plume affecting the direction of the dispersion (Figure 3). Moreover, the presence of corners enable the particulate matter to get confined to a particular region within the deep open pit till they reach a particular height where the effect of topography gets diminished and plume expansion is observed. This is called the venturi effect (Appleton et al, 2006). The sloping terrain may result in katabatic and anabatic flows (i.e drainage of air down or uphill sides in response to changing vertical temperature profiles). Further, the terrain elevation may either restrict or exacerbate aereal dispersion when the lower boundary layer heights confine the particulate plume closer to the terrain surface.

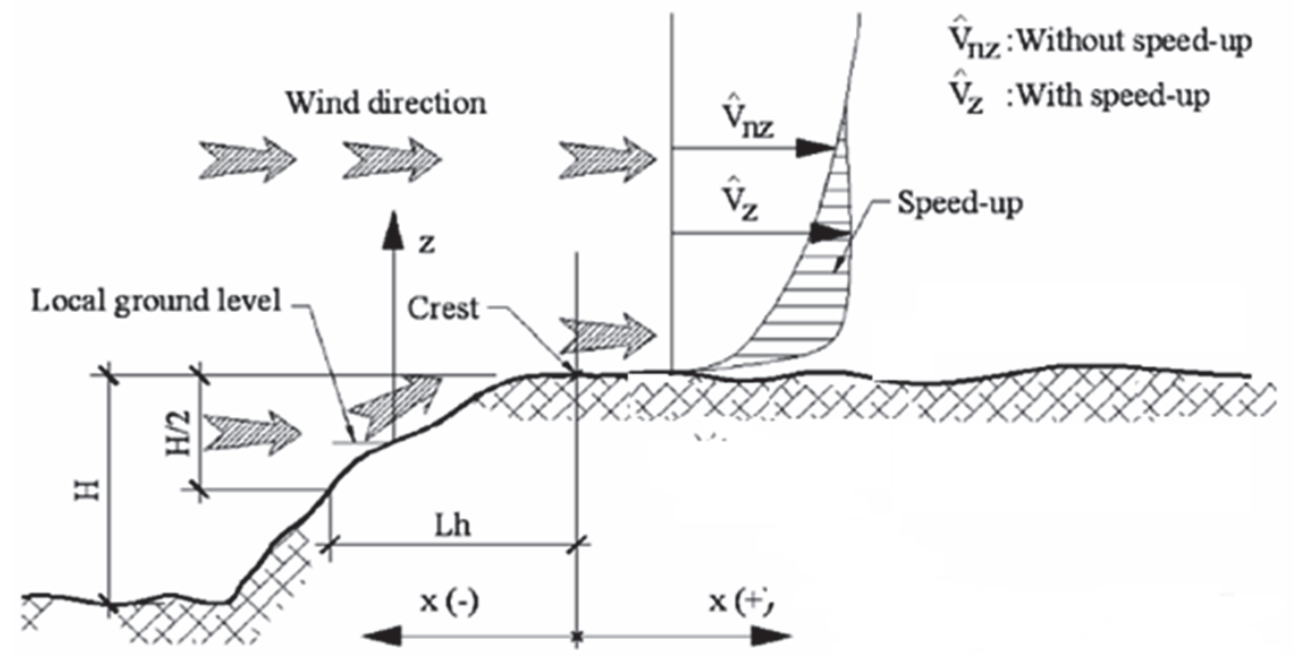

Fig. 2. Wind speed due to the presence of slopes (Ngo and Lechford, 2008)

\subsubsection{The depth of the open pit coal mine}

When the depth of a mining pit is increased, an open air space with characteristic properties under extreme physical conditions is created (Baklonov, 1986). Under such conditions, the 
depth of the open pit affects the penetration angle $a$, which is defined as the angle of the shear interface line defining the boundary between the penetration of the external ABL velocity profile and the induced leeward in pit recirculation zone (Figure 4). Further, the depth has a significant effect on the air flow patterns within the mine. In case of shallow pits, air flow expands gradually, without any gap in mine area. There is a little compression of flow line on outlet area due-to action of flow inertia. In case of medium depth mines, fluid vortex has shape of flattened ellipse whose height and width differ significantly.
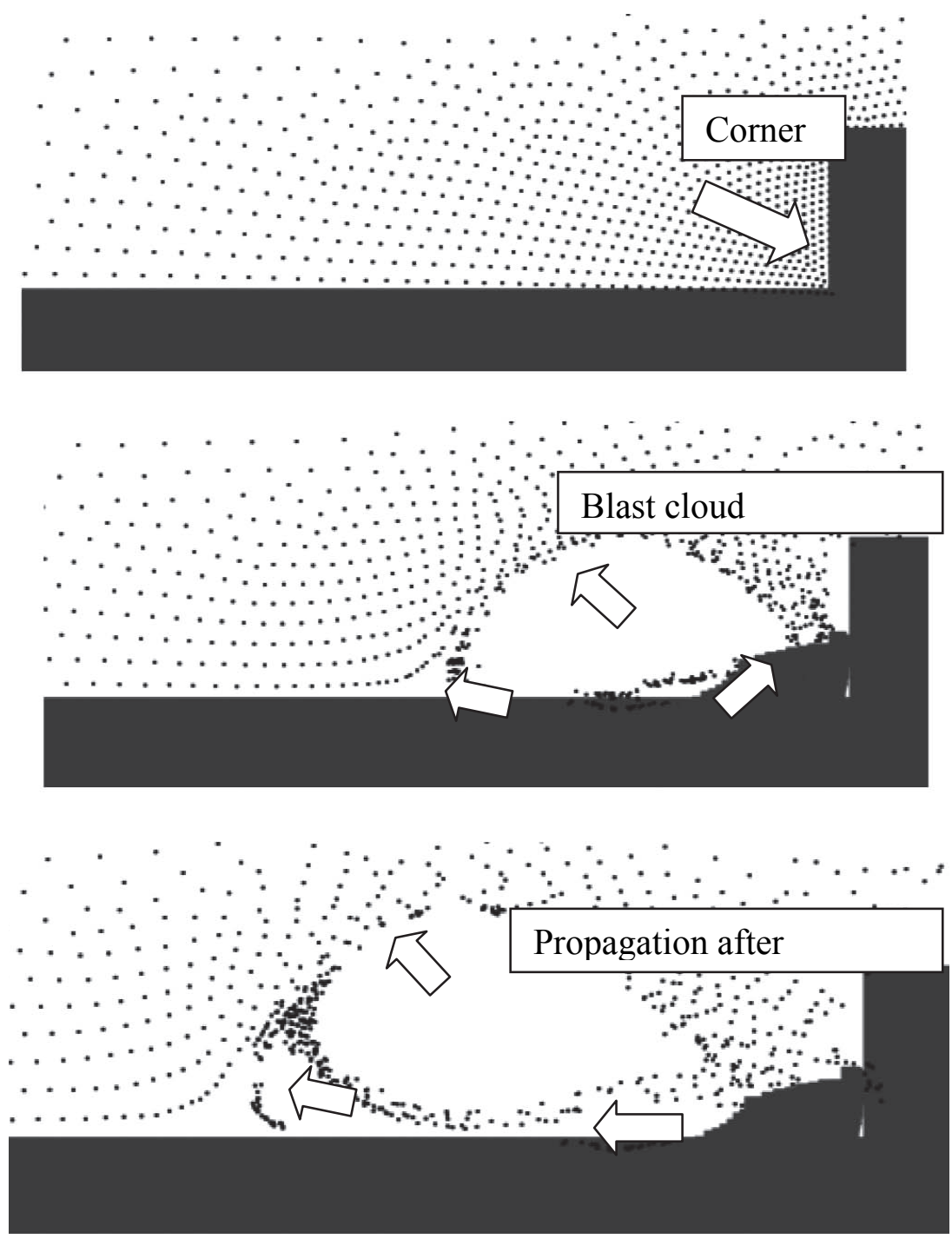

Fig. 3. Effect of local deflection on the dispersion of particulate plume (Appleton et al, 2006) 
The viscous forces, pressure gradients and turbulence friction act as driving mechanisms (Figure 5). Close to leeward side, there is detached point area of thickened boundary layer. In windward side zone, there is flow connection point zone, near which part of flow turns back in detached vortex zone and part moves up and toward exit from zone (Markov et al, 1978). Moreover, for the same incoming airflow and the same slope angle, the mechanical forcing and turbulence increase with increase in the depth, which will result in or strengthen the reverse airflow and the recirculation (Shi et al, 2000).

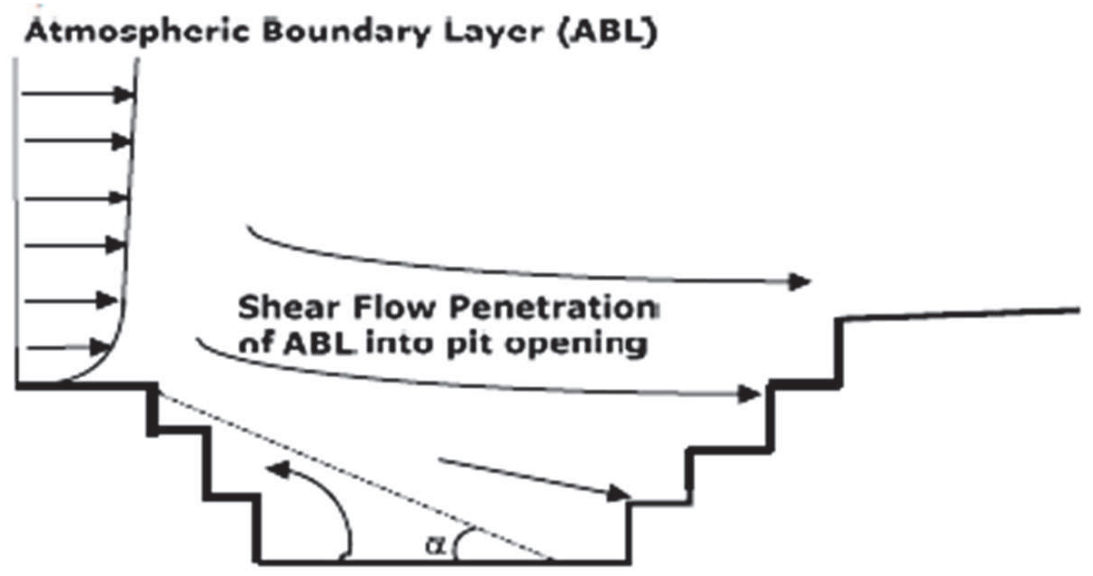

Leeward Recirculation Flow Zone

Fig. 4. Penetration angle $\mathrm{a}$ in deep open pit mines (Peng and Lu, 1995)

\subsubsection{Width and breadth of deep open pit coal mine}

The width and breadth of the coal mine affects the rate of cooling in the mine, which is defined in terms of terrain amplification factor (TAF) (Equation 1).

$$
\mathrm{TAF}=3 \mathrm{~W}_{1} \mathrm{~B}_{1} /\left[\mathrm{W}_{1} \mathrm{~B}_{1}+\mathrm{W}_{2} \mathrm{~B}_{2}+\left(\mathrm{W}_{1} \mathrm{~B}_{1} \mathrm{~W}_{2} \mathrm{~B}_{2}\right)^{1 / 2}\right]
$$

where $W_{1}$, width of the mine at the top,

$\mathrm{B}_{1}$, breadth of the mine at the top,

$\mathrm{W}_{2}$, width of the mine at the bottom and

$\mathrm{B}_{2}$, breadth of the mine at the bottom.

\subsubsection{Aspect ratio}

The aspect ratio decides whether the air outside the pit intrudes into the pit or not. Recirculation zones are formed based on the aspect ratio of the pit (Figure 6). The formation of the secondary vortex has been observed as the aspect ratio increases. It is due to the fact that the penetration of the external boundary layer in to the cavity acts as a driving force for the formation of the secondary vortex. 

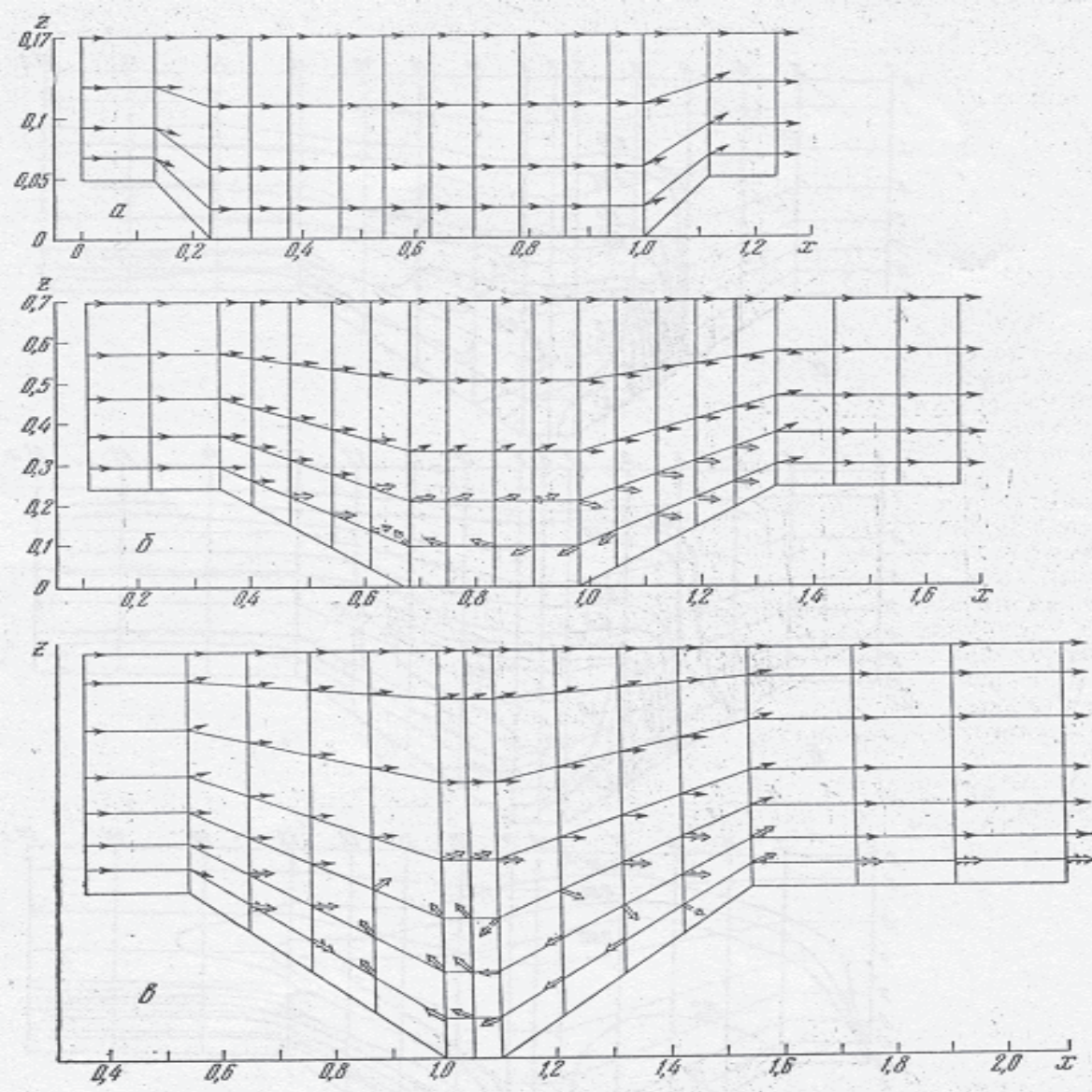

Fig. 5. Vector fields of speed of steady-state flow processes in the deep open pit mines (Markov et al, 1978).

\subsubsection{Effect of overburden dumps}

Baklonov and Regina (1998) has investigated the effect of overburden dumps on dispersion and observed that the velocity increases as the wind passes through the dump from bottom to the top. Further, if the dump is located at the upwind side, it alters the wind flow and turbulence characteristics from those measured at the nearest meteorological station. The rough terrain changes the wind speed directions and turbulence characteristics and enhance mixing in the air stream (Kirchgessner et al, 1993). Huertas (2009) has observed the effect of deposition by altering the area of dumps which shows that the retention of particulates is dependent on the volume and the area of the overburden. 

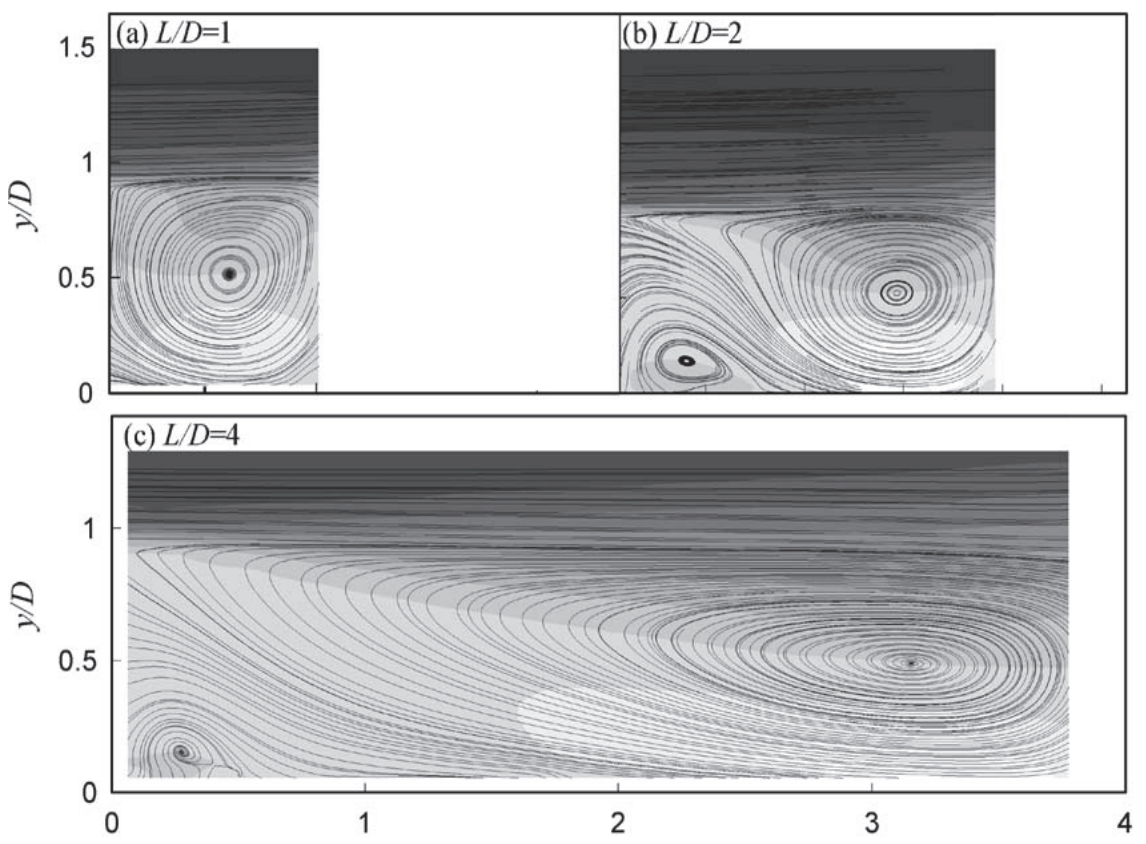

Fig. 6. Effect of aspect ratio on the flow (Kang \& Sung, 2009)

\subsubsection{Meteorological effects}

\subsubsection{Wind speed \& direction}

It is observed that the wind speed is positively correlated and reduced to three fourth after entering into the pit (USEPA, 1985). The higher wind speeds attribute to the lesser deposition fluxes and lesser concentrations of particulates due to the elongation of the particle plumes generated inside the pit. Further, higher wind speeds cause an elongation of particulate plume and a reduction in the airborne concentration and deposition flux gradients observed near source (Appleton et al, 2006). The wind direction inside and outside the pit are not positively co- related. The wind direction displaces the air to a particular direction, thus causing thermal inhomogeneities within the open pit mine. The standard deviations of vertical and horizontal wind directions enable the prediction of the deviation of the wind from its original direction. It has been found that the wind direction changes by an angle of $60^{\circ}$ with respect to the direction at the surface (USEPA, 1985).

\subsubsection{Stability}

The stability affects the flow in the mine by influencing the vertical motion. It is observed that stable atmosphere suppresses the vertical motion of the pollutants resulting into deposition of pollutants. However, for unstable and neutral conditions, the escape fraction of the particulates has been found to be more. Under the effect of stratification, the flows in a pit are expected to be similar to the night time flows occurring in the mountains due to the accumulation of cold air and nocturnal cooling (Grainger \& Merony, 1993). Further, the inversion depth and strength tend to be stronger than those found over valleys or flat terrain 
(Maki et al, 1986). Grainger \& Merony (1993) have observed that inversion effects are more predominant in pits rather than on flat terrains. The occurrence of the inversion in the pit depends upon the Froude number (Fr), which is independent of the pit geometry. Further, it has been found that the coal pit dispersion under stably-stratified conditions is dominated by the buoyancy-inertia forces (Equation 2).

$$
F r=U_{h}\left[\frac{g h\left(\theta_{h}-\theta_{0}\right)}{\theta}\right]^{-1 / 2}
$$

where,

$\theta_{h}$, is the air temperature at the ridge top

$\theta_{0}$, is the air temperature at the valley floor

If $\mathrm{Fr}>1.6$, then inversion is swept away;

If $1.3<\mathrm{Fr}<1.6$, the air in the basin is coupled to the air above the basin;

and if $\mathrm{Fr}<1.3$, the air is totally decoupled

Further, the dispersion is dependent on the pasquill stability classes (Table 3).

\begin{tabular}{|c|c|}
\hline Stability class & Effects on dispersion in the coal mines \\
\hline A & $(2),(3),(4)$ \\
\hline B & $(2),(3),(4)$ \\
\hline C & $(2),(4)$ \\
\hline D & $(2)$ \\
\hline E & $(1),(2),(3),(5)$ \\
\hline F & $(1),(3),(5)$ \\
\hline G & $(1),(3),(5)$ \\
\hline
\end{tabular}

Table 3. Factors affecting dispersion for different stability classes

Where,

1. Aids dispersion if terrain is flat and restricts dispersion if the terrain is rising

2. Impact by particulate deposition

3. Impact by airborne particulates

4. Higher values of Surface heat flux aids dispersion due to the generation of upward air currents

5. Lower values of surface heat flux restricts aerial dispersion

\subsubsection{Thermal effects}

The combined action of the mechanical shear of the ABL across the surface opening and the thermal buoyancy forces produce the air flow by the differential heating in the pit surface (Silvester et al, 2009). Solar energy controls the physical processes of the atmosphere through the mediation of the surface. Open pit mining modifies the ground surface material composition, structure, cover, morphology, colour which affects the meteorological processes and also affects the partitioning of the incoming solar radiation into sensible and latent heat fluxes which affects the amount of solar radiation that is scattered back to the space. The airspace of a mine pit tends to warm up rapidly when insolation is intense, while 
cold air tends to accumulate in it when insolation is low or missing (Loska, 2007). More over the solar radiation has different effects during different seasons, which affects the total amount of air heated in the open pit mine (Figure 7). Further, the solar radiation influences many physical processes. The physical processes and their interactions form chains of interactions, which are highly dependent on the type of the terrains and surrounding conditions, like radiation (Figure 8).

\subsubsection{Thermal inhomogenities}

Due to the combined effect of nonuniform horizontal temperature field and the wind direction, thermal inhomogenities are created in the deep open pit. With an active influx of solar radiation, the effect of thermal forces is manifested not only as the component of the resulting wind velocity, but also affects the stability within the deep open pit. The inhomogenities can be classified into four types

1. With increasing depth, the air temperature rises by a value greater than the adiabatic temperature gradient

2. The air temperature increases with depth

3. The air temperature remains constant with depth

4. The air temperature decreases with depth

Thus two main types of stratification exist within the deep open pit space: unstable (lst type) and stable (2nd, 3rd, and 4th types), which may be present in single form or as combinations (Bitkolov, 1969).

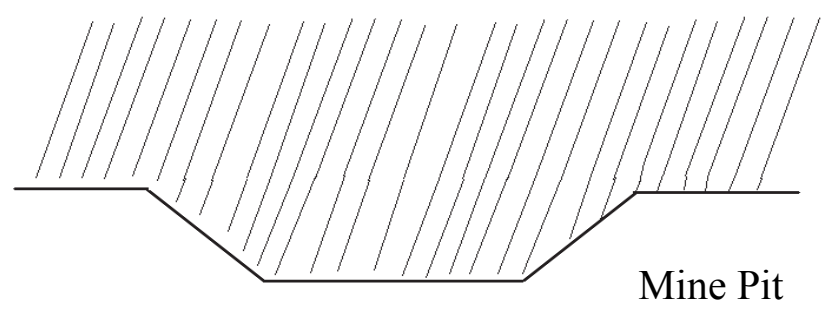

\section{Radiation \\ during}

Summer

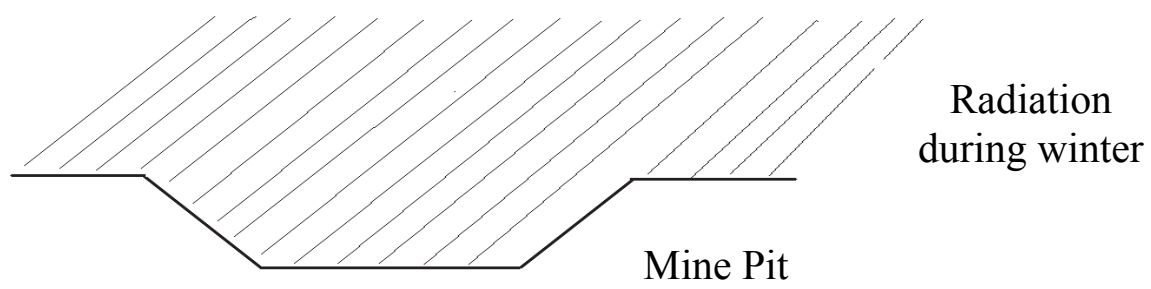

Fig. 7. Effect of solar radiation during winter and summer in the mine pit 


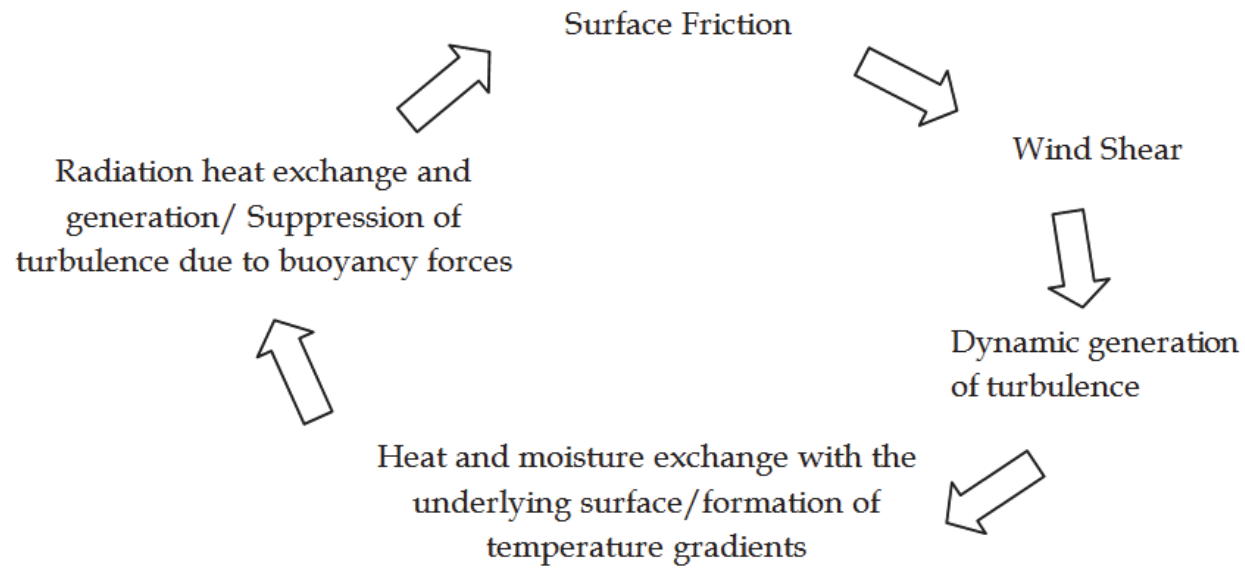

Fig. 8. Chains of interactions of physical processes (Zilitinkevich, 1990)

\section{Modelling the flow in open pit coal mines}

Dispersion uses mathematical equations describing the atmosphere along with chemical and physical processes to estimate and predict concentrations at various locations. Dispersion models for predicting particulate concentrations have been discussed by Mikkelson (2003), Reed (2005) and Holmes \& Morwska (2006). The conventional models of dispersion for the plane terrain retain flow stationarity and horizontal uniformity hypothesis. As a result, they are no longer valid when the open pit terrain complexity produces mesoscale and local scale circulations. Most of the conventional models employ the hydrostatic approximation which neglects the vertical acceleration versus the pressure gradient and the gravitational terms. This implies that the vertical scale of motion is smaller than the horizontal scale. This applicability of the hydrostatic approximation depends not only on the geometry of the wind, but also on the vertical stability. Hence the non-hydrostatic multiscale approach is preferred. Penenko \& Aloyan (1976) have proposed a three-dimensional non stationary model for mesoscale boundary layer of atmosphere. The model includes the effects of horizontal gradients of potential temperatures, stratification parameters and vertical and horizontal turbulence factors. Later, a two dimensional model has been proposed by improving this model to allow considering substantial two-dimensional effects of flow in the deep open pit coal mines having complex geometry (Markov et al, 1978). Further, Aloyan et al (1982) have used a fictious region method in which the equations are generated in a rectangular cartesian coordinate system. The model has helped in simulation of the winds in a quarry under various thermal conditions (stable, unstable and equilibrium stratifications) and investigating the effects of the external wind on the temperature inversion. The model describes the flow in deep open pit coal mines and helps analyzing influence of their geometric parameters by detailed consideration of characteristics of impurity sources. Later, these mathematical models describing the dynamics of the atmosphere in the deep open pits have been combined with the system for calculating the thermal and radiational balance on the surface (Baklonov, 1984). Baklonov (1986) has also 
established a thermodynamic model for the deep open pit ventilation systems. The model simulates the diurnal changes that take place during the differential solar heating of the surface during the day and the release of this energy during the evening. Further, Baklanov (1995) has presented the results of a series of numerical modeling case studies that consider the pollutant dispersion within naturally ventilated deep open pits, for a range of different external wind speeds and directions, internal thermal stratifications, recirculation flow regimes and the interaction of local open pit thermal circulations with the external atmospheric flow field. In a later study, a high-resolution, non-hydrostatic and three dimensional PBL model for characterizing the flow in the open mine has been developed by Shi et al (2000). The classical 2-D Navier-Stokes equation and a 0-D bond-graph model have been used to investigate the flow dynamics of the mines by discussing the interconnections, nonlinearities and turbulence. The 0-D model efficiently provides for a fast and representative global model for the mine ventilation problem (Witrant et al, 2008). Table 4 summarizes the various studies conducted on open pit mines.

\subsection{The model and its features}

The governing equations which serve the basis of modeling the deep open pit mines have been described (Markov et al, 1978). Equations 3-6 include non stationary hydrodynamic equations of Navier-Stokes, continuity equation for incompressible fluid and equation for carryover of impurity concentration in plane cartesian system of coordinates.

$$
\begin{gathered}
\frac{\partial u}{\partial x}+\frac{\partial w}{\partial z}=0 \\
\frac{\partial u}{\partial t}+u \frac{\partial u}{\partial x}+w \frac{\partial u}{\partial z}=-\frac{\partial p}{\partial x}+\frac{1}{\operatorname{Re}_{r}}\left[\frac{\partial}{\partial x}\left(k \frac{\partial u}{\partial x}\right)+\frac{\partial}{\partial z}\left(k \frac{\partial u}{\partial z}\right)\right] \\
\frac{\partial w}{\partial t}+u \frac{\partial w}{\partial x}+w \frac{\partial w}{\partial z}=-\frac{\partial p}{\partial z}+\frac{1}{R e_{r}}\left[\frac{\partial}{\partial x}\left(k \frac{\partial w}{\partial x}\right)+\frac{\partial}{\partial z}\left(k \frac{\partial w}{\partial z}\right)\right] \\
\frac{\partial c}{\partial t}+u \frac{\partial c}{\partial x}+w \frac{\partial c}{\partial z}=\frac{1}{\operatorname{Pr}_{d} \operatorname{Re}_{r}}\left[\frac{\partial}{\partial x}\left(k \frac{\partial c}{\partial x}\right)+\frac{\partial}{\partial z}\left(k \frac{\partial c}{\partial z}\right)\right]
\end{gathered}
$$

where,

$\mathrm{u}, \mathrm{w}$ - projection of velocity vectors on horizontal and vertical directions (m/sec);

$\mathrm{p}$ - deviation of pressure from hydrostatic (Kpa);

c - specific volumetric concentration of impurities $\left(\mathrm{g} / \mathrm{m}^{3}\right)$;

$\mathrm{k}$ - turbulent kinematic viscosity factor $(\mathrm{kg} / \mathrm{m} / \mathrm{s})$;

$\mathrm{L}_{\mathrm{B}}$ - characteristic longitudinal dimension of upper section of the mine(m);

$\operatorname{Re}_{\mathrm{T}}=L_{B} u_{\infty} / k_{\infty}$, Reynold's turbulence number;

$\operatorname{Pr}_{d}=k / k_{e}$, Prandtl's diffusion number, which characterizes ratio between turbulence viscosity factor $k$ and diffusion factor $k_{\mathrm{e}}$.

For the values $\mathrm{LB} / u_{\infty}, u_{\infty}, \rho_{\infty} u_{\infty}^{2}$ and $\mathrm{k}_{\infty}$, the subscript $\infty$ characterizes the parameters of incident flow.

This model overcomes the limitations of the single dimensional models, which does not allow considering substantial two-dimensional effects of flow in open pit coal mines having 
complex geometry of surface. This approach helps in solving wide range of problems concerning natural air exchange. The model describes dispersion in deep open coal mines and helps analyzing influence of their geometric parameters on natural air exchange, by considering pollutant characteristics. Thus, the model with sufficient practical accuracy describes the natural ventilation process and can be useful for calculation of flows in deep open pit coal mines.

\subsection{The model limitations}

The present model has no provision for considering the effects of settling of the particles. Moreover, it does not consider: stability (temperature effect)/ buoyancy effects that govern the dispersion of PM within the mine boundary. The model can be modified to incorporate the effects of the buoyancy interms of the temperature difference (Equation 5). Due to the temperature difference existing between the two vertical layers of the atmosphere within the mine, the buoyant force may rise the particle vertically (Grainger \& Merony, 1993). Moreover, the temperature equation (Equation 6) can be modified to incorporate the effect of the vertical temperature gradient and the existing temperature gradient. These limitations are presently being addressed as Ph.D problem in Civil Engineering Department at IIT Delhi (Chinthala, 2010).

\begin{tabular}{|c|c|c|}
\hline AQ model/ Technique & Type & Reference \\
\hline 3-D Non Hydrostatic Model & Numerical & Gresho et al (1976) \\
\hline Non Stationary N-S model & Numerical & Markov et al (1978) \\
\hline 3-D Non Stationary Model & Numerical & Aloyan et al (1982) \\
\hline Cole and Fabrick & Box model & Cole \& Fabrick (1984) \\
\hline 2-D Hydrostatic Model & Numerical & Herwehe (1984) \\
\hline ISC3 & Gaussian & USEPA(1995c) \\
\hline Wind Tunnel & Physical & Peng \& Lu (1995) \\
\hline 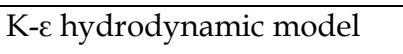 & Numerical & Fomin (1996) \\
\hline Wind Tunnel & Physical & Shi et al (2000) \\
\hline Wind Tunnel & Physical & Grainger \& Merony (2003) \\
\hline Fabrick & Gaussian & Reed (2005) \\
\hline Gelekin & Gaussian & Reed (2005) \\
\hline Herwere & Eulerian & Reed (2005) \\
\hline Kalgoorlie & Unknown & Reed (2005) \\
\hline PerieraSoares\&Branquinho & Gaussian & Reed (2005) \\
\hline Winges & Gaussian & Reed (2005) \\
\hline 2-D Non Hydrostatic model & Numerical & Kharytonov et al (2005) \\
\hline ADMS & Gaussian & Appleton et al (2006) \\
\hline RANS & Numerical & Bodnor et al (2008) \\
\hline CFD & Numerical & Silvester et al (2009) \\
\hline k- $\varepsilon$ model & Numerical & Kakosimos et al (2011) \\
\hline
\end{tabular}

Table 4. Modelling studies on open pit mines 


\section{Conclusions}

Simulating the dispersion in deep open pit coal mines is an effective tool to give advanced warning of potential emission problems and providing the basis for future planning applications. The meteorological conditions within an open pit coal mine are significantly affected by temperature (stability) and roughness conditions that generate complex fluid flows phenomenon e.g. separation of atmospheric boundary layer, recirculation, resuspension and settling of particulates. The complex geometry, uncontrolled wind flows and different operations taken place within the deep open pit coal mines, makes it extremely difficult to measure the particulates. Therefore, an appropriate mathematical model is needed which may predict the complex processes in the near field regions of the deep open pit coal mines effectively. The fundamental understanding of the microclimate that is created in the deep open pit mine due to influence of the external ABL and the contributions of the mechanical and thermal forces present, can be achieved by developing a dynamic numerical based inverse hill model to investigate the complex wind flows and dispersion mechanisms.

\section{References}

Aloyan, A.E., Baklonov, A.A., and Penenko, V.V. (1982). Application of fictious domain method in numerical simulation problems of open cast mine ventilation, Meteoroliogiya i gidrologiya, Vol., 7, pp. 42-49.

Appleton, T., Kingman, S., Lowndes, I., and Silvester, S. (2006). The development of a strategy for the simulation of fugitive dust emissions from in-pit quarrying activities: a UK case study, International Journal of Mining, Reclamation and Environment, Vol., 20 (1), pp. 57-82.

Baklanov, A.A. (1984). A Method For Evaluating The Energy Characteristics Of The Air In An Open Pit Mine, Fiziko-Tekhnicheskie Problemy Razrabotki Poleznykh Iskopaemykh, No. 1, pp. 73-78.

Baklonov, A. (1986). A method for evaluating the energy characteristics of the air in an open pit mine, Journal of Mining Science, 22,1, pp.66-70.

Baklanov, A. (1995). Numerical of atmosphere processes in mountain cirques and open pits, Proceedings of International Conference on Air Pollution, pp. 231-238, Greece, Porto Carras.

Baklonov, A. and Rigina, O. (1998). Environmental of dusting from the mining and concentration sites in the kola peninsula, North west Russia, Proceedings in IUAPPA-NACA, Vol 1, 4F-3, The XI world clear air and environment congress, South Africa, 14-18 september, 1998, Durban.

Bitkolov, N.Z (1969). Wind and Temperature of quarry atmospheres. Fiziko-Tekhnicheskie Problemy Razrabotki Poleznykh Iskopaemykh, No. 5, September-October, pp. 66-73.

Bodnor, T., Benes, L. and Kozel, K. (2008). Numerical simulation of flow and pollution dispersion in the area of opencast coal mine, American Institute of Physics, Conference Proceedings, 1048, pp.100-103.

Castro, I.P and Apsley, D.D. (1997). Flow and dispersion over topography: A comparision between numerical and laboratory data for two dimensional flows, Atmospheric Environment, Vol., 31, 6, pp. 839-850.

Chang, P.K. (1970). Seperation of flow, Pergamon Press, Oxford, London. 
Chinthala, S. (2010). Near field Simulation of $\mathrm{PM}_{10}$ Dispersion in deep open pit coal mines. Unpublished report, IIT Delhi.

Chowdhary, K.K. (1977). An experimental and theoretical investigation of turbulent seperated reattached and redeveloped flows with transverse rectangular cavities. Phd thesis, Indian Institute of Technology Delhi, New Delhi.

Cole, C., and Fabrick, A. (1984). Surface mine pit retention. Journal of the Air Pollution Control Association, Vol., 34, 6, pp.674-675.

Fomin, A.A. (1996). Modeling of a natural convection in an open pit, Izvestiya Rossiiskoi Akademii Nauk, Mekhanika Zhidkosti i Gaza, Vol., 4, pp.12-20.

Falk, L.H and Jurgelski, W. Jr (1979). Health effects of coal miing and combustion: Carcinogens and cofactors. Environmental Health Perspective, 33, pp 203-226.

Ghose, M. K. and Majee, S. R. (1998). Assessment of dust generation due to opencast coal mining - an Indian case study, Environmental Monitoring and. Assesment. Vol., 61, pp.255-263.

Ghose, M.K., and Majee, S.R. (2007). Characteristics of Hazardous Airborne Dust Around an Indian Surface Coal Mining Area, Environmental Monitoring and Assessment, Vol., 130, pp.17-25.

Grainger, C. and Meroney, R.N. (1993). Dispersion in an open-cut coal mine in stably stratified flow. Boundary-Layer Meteorology, Vol., 63, pp.117-140.

Gresho, P.M., Lee, R.L. and Sani, R.L. (1976). Modelling the planetary boundary layer using the galerkin finite element model, Third Symposium on Atmospheric turbulence diffusion and Air quality, Raleigh, NC, October 26-29, 1976.

Hanna, S. R., Briggs, G.A., and Hosker, R. F. (1982). Handbook on Atmospheric Diffusion Technical Information Center, U.S. Department of Energy DOE/TIC 11223.

Herwehe, J.A. (1984). Numerical Modelling of Turbulent Difussion of fugitive dust from an idealized open pit mine, Masters thesis, Iowa state university, Ames, Iowa.

Holmes, N.S. and Morawska, L. (2006). A review of dispersion and its application to the dispersion of particles: An overview of different dispersion models available, Atmospheric Environment, Vol., 40, pp.5902-5928.

Huertas (2009). Dispersion and deposition of particulate material in areas open pit mining using CFD. Eighth National Congress of Science and Technology of Coal and Alternative Fuels, November 12-13.

Kakosimos, K.E., Assael, M.J., Lioumbas, J.S and Spiridis, A.S (2011). Atmospheric dispersion of the Zugitive particulate matter from overburden dumps with numerical and integral models, Atmospheric Pollution Research, Vol., 2, pp.24-33.

Kang, W and Sung, H.J. (2009). Large scale structures of turbulent flows over an open cavity, Journal of Fluids and Structures, Vol., 25, pp.1318-1333.

Kharytonov, M., Zberovsky, A., Drizhenko, A. and Babiy, A. (2005). Air pollution assessment inside and around iron ore quarries, in I. Farago et al. (eds.), Advances in Air Pollution Modeling for Environmental Security, pp.263-274.

Kirchgessner, D.A., Piccot, S.D and Chadha, A. (1993). Estimation of methane emissions from a surface coal mine using open-path FTIR spectroscopy and modeling techniques, Chemosphere, Vol., 26, 1-4, pp.23-44.

Larcheveque, L., Sagaut, P., Mary, I., Labbe, O and Comte, P. (2003). Large-eddy simulation of a compressible flow past a deep cavity, Physics of Fluids, Vol., 15, 1, pp.193-210. 
Lazar, E., Elliott, G., and Glumac, N. (2008). Control of the shear layer above a supersonic cavity using energy deposition, AIAA Journal, Vol., 46, pp. 2987-2997.

Loska, G. (2007). Variations in microclimate modified by open-cast mining: case studies from hungary, Gogr.Fis. Dinan.Quat, Vol., 30, pp 215-218.

Markov, V.A., Potashnik, E.L. and Rivkind, V.Y. (1978). Two dimensional mathematical model of natural ventilation processes in opencast mines, Atmosphere and Ocean physics, Vol., 14-5.

Mcquain, W.D., Calvin, I., Ribbens, I.C., Wang, Y and Watson, L.T. (1994). Steady visoucs flow in a trapezoidal cavity, Computers Fluid, Vol., 23, No. 4, pp. 613-626.

Mikkelsen, T. (2003). Dispersion of pollutant in the atmosphere, Position paper, Atmospheric physics division, Denmark.

Merony, R.N. and Grainger, C. (1992). Night time flow and dispersion over large basins or mining pits, symposium on measurement and modeling of environmental flows, ASME winter annual meeting, Anaheim, California, November, pp. 8-13.

Maki , M., Harimaya, T and Kikuchi, K. (1986). Heat budjet studies on nocturnal cooling in a basin, Journal of Meteorolgocial society of Japan, 64, 5, 727-740.

Ngo, T and Letchford, C. (2008). A Comparison of topographic effects on gust wind speed. Journal of Wind Engineering and Industrial Aerodynamics, 96, pp. 2273-2293.

Penenko, V.V. and Aloyan, A.E. (1976). Numeric method for calculating fields of meteorological elements in atmosphere boundary layer, Meteorology and Hydrology, 6, pp.11-26.

Peng, X. and Lu, G. (1995). Physical of natural wind and its guide in a large open pit, Journal of Wind Engineering and Industrial Aerodynamics, 54/55, pp. 473-481.

Reed, W. (2005) Significant Dust Dispersion Models for Mining Operations, Tech.Rep. IC 9478. NIOSH, Pittsburgh, PA, USA.

Richardson, L.F. (1926). Atmospheric diffusion shown on a distance neighbour graph, Proc. R. Soc. Lond., Ser. A, 110, pp. 709-737.

Roberts, O.F.T. (1923). The theoretical scattering of smoke in a turbulent atmosphere, Proc. $R$. Soc. (A), 104, pp. 640-654.

Roy, S., Adhikari, G.R., Renaldy, T.A and Jha, A.K. (2011). Development of multiple regression and neural network models for assessment of blasting dust at a alarge surface coal mine. Journal of Environmental science and Technology, 4(3), pp 284-301.

Shi, Y., Feng, X., Wei, F., and Jiang, W., (2000). Three-dimensional non-hydrostatic numerical simulation for the PBL of an open-pit mine, Boundary-Layer Meteorology, 94, pp. 197-224.

Silvester, S.A., Lowndes, I.S., Hargreaves, D. M. (2009). A computational study of particulate emissions from an open pit quarry under neutral atmospheric conditions, Atmospheric Environment, Volume 43, Issue 40, December 2009, pp. 6415-6424.

Taylor, G.I. (1921). Diffusion by continuous movements, London Mathematical Society, 20, pp.196-211.

Trivedi, R., Chakraborthy, M. K., and Tewary, B. K., (2009). Dust deposition using fugitive dust model at an opencast coal project of western coalfields limited, India, Journal of Scientific and Industrial Research, Vol., 68, pp.71-78.

Turner D. B. (1994). Workbook of atmospheric dispersion estimates. li.S. Environmental Protection Agency, AP-26, Warren Spring Laboratory, National survey of smoke and sulphur dioxide, Instruction manual. 
USEPA (1976). Evaluation of Fugitive dust emission from mining, 68-02-1321.

USEPA (1980). The Environmental Impact of Coal Transfer and Terminal Operations, 600/S7-80-169.

USEPA (1985). Dispersion of Airborne particulates in surface mines, 450/4-85-001.

USEPA (1995c). User's guide for the industrial source complex (ISC3) dispersion models. Vol. II. Description of model algorithms. Research Triangle Park, NC: U.S. Environmental Protection Agency, Office of Air Quality Planning and Standards, Emissions, Monitoring, and Analysis Division, EPA publication No. EPA-454/B95-003b.

Witrant, E., Johansson, K. and the HynX team, (2008). Air flow in deep wells: Application to mining ventilation, IEEE Conference on Automation Science and Engineering (CASE), USA, August 23-26, Washington DC. 


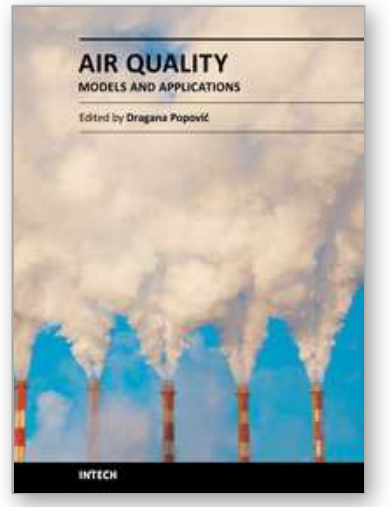

\author{
Air Quality-Models and Applications \\ Edited by Prof. Dragana Popovic
}

ISBN 978-953-307-307-1

Hard cover, 364 pages

Publisher InTech

Published online 09, June, 2011

Published in print edition June, 2011

Air pollution has been a major transboundary problem and a matter of global concern for decades. High concentrations of different air pollutants are particularly harmful to large cities residents, where numerous anthropogenic activities strongly influence the quality of air. Although there are many books on the subject, the one in front of you will hopefully fulfill some of the gaps in the area of air quality monitoring and modeling, and be of help to graduate students, professionals and researchers. The book is divided in five sections, dealing with mathematical models and computing techniques used in air pollution monitoring and forecasting; air pollution models and application; measuring methodologies in air pollution monitoring and control; experimental data on urban air pollution in China, Egypt, Northeastern U.S, Brazil and Romania; and finally, the health effects due to exposure to benzene, and on the influence of air pollutants on the acute respiratory diseases in children in Mexico.

\title{
How to reference
}

In order to correctly reference this scholarly work, feel free to copy and paste the following:

Sumanth Chinthala and Mukesh Khare (2011). Particle Dispersion Within a Deep Open Cast Coal Mine, Air Quality-Models and Applications, Prof. Dragana Popovic (Ed.), ISBN: 978-953-307-307-1, InTech, Available from: http://www.intechopen.com/books/air-quality-models-and-applications/particle-dispersion-within-a-deepopen-cast-coal-mine

\section{INTECH}

open science | open minds

\section{InTech Europe}

University Campus STeP Ri

Slavka Krautzeka 83/A

51000 Rijeka, Croatia

Phone: +385 (51) 770447

Fax: +385 (51) 686166

www.intechopen.com

\section{InTech China}

Unit 405, Office Block, Hotel Equatorial Shanghai

No.65, Yan An Road (West), Shanghai, 200040, China

中国上海市延安西路65号上海国际贵都大饭店办公楼 405 单元

Phone: +86-21-62489820

Fax: $+86-21-62489821$ 
(C) 2011 The Author(s). Licensee IntechOpen. This chapter is distributed under the terms of the Creative Commons Attribution-NonCommercialShareAlike-3.0 License, which permits use, distribution and reproduction for non-commercial purposes, provided the original is properly cited and derivative works building on this content are distributed under the same license. 